\title{
Genetic Interaction of the Fusiform Rust Fungus with Resistance Gene Fr1 in Loblolly Pine
}

\author{
Thomas L. Kubisiak, Henry V. Amerson, and C. Dana Nelson
}

First author: Research Geneticist, U.S. Department of Agriculture (USDA) Forest Service, Southern Institute of Forest Genetics, 23332 Highway 67, Saucier, MS 39574; second author: Department of Forestry, North Carolina State University (NCSU), 840 Main Campus Drive, 2500 Partners II Bldg., NCSU Centennial Campus, Raleigh 27695; and third author: Research Geneticist and Project Leader, USDA Forest Service, Southern Institute of Forest Genetics, 23332 Highway 67, Saucier, MS 39574. Accepted for publication 12 December 2004.

\begin{abstract}
Kubisiak, T. L., Amerson, H. V., and Nelson, C. D. 2005. Genetic interaction of the fusiform rust fungus with resistance gene $F r 1$ in loblolly pine. Phytopathology 95:376-380.

We propose a method for defining DNA markers linked to Cronartium quercuum f. sp. fusiforme avirulence (Avr) genes. However, before this method can be successfully employed, a spore competition study was needed to determine the genetic composition of single pycnial drops and multiple drops on single galls when using the standard inoculation procedure, whether virulent (avr1) basidiospores ever predispose some resistant $(F r 1 / f r 1)$ trees to infection by avirulent (Avr1) basidiospores, and

average in $>4$ infection events per tree. Due to multiple infections within a single gall, an individual pycnial drop cannot be assumed to consist of spores from only a single haploid pycnium. Roughly $57 \%$ of the drops harvested were found to consist of more than one haploid genotype, most likely due to the physical mixing of spores from genetically different pycnia. Most importantly, although multiple infections do occur in the formation of a single gall, there is no evidence to suggest that the genetics of the proposed gene-for-gene interaction are compromised. Only avr 1 basidiospores were observed to cause infection on $\operatorname{Fr} 1 / f r 1$ trees, whereas both $a v r 1$ and Avr1 basidiospores were observed to cause infection on $f r 1 / f r 1$ trees, albeit not at equal frequencies.
\end{abstract} whether $a v r 1$ and $A v r 1$ basidiospores equally infect susceptible $(f r 1 / f r 1)$ trees. Results of this study suggest that multiple infections within a single gall are common using the concentrated basidiospore system, resulting on
Additional keywords: gametothalli, infection haplotype, Pinus taeda.
Fusiform rust incited by the biotrophic, macrocyclic, heteroecious fungus Cronartium quercuum (Berk.) Miyabe ex Shirai f. sp. fusiforme is a disease endemic to oaks and pines of the southeastern United States. Damage on the telial or repeating host (red oaks) is confined to leaf spotting, whereas damage on the aecial or nonrepeating host (pines) results in the formation of galls on stems and/or branches of infected trees. These swellings can girdle and directly kill infected trees or weaken the stem and hence predispose them to future wind damage. Current data suggest that the interaction of specific dominant genes (fusiform rust resistance genes or Fr genes; according to nomenclature established by Wilcox et al. [12]) in the aecial host and specific genes (avirulence genes or Avr genes) in the pathogen determine whether disease will occur $(4,6,9,12)$. Based upon this model, a host tree carrying a resistance allele for a specific Fr gene ( $\mathrm{Fr} / \mathrm{Fr}$ or Fr/fr) is only resistant if the pathogen genotype is avirulent (Avr) to the resistance allele of that specific Fr gene. A virulent (avr) pathogen is capable of inciting disease on the otherwise Fr resistant tree. Despite tremendous progress made on mapping specific Fr genes in the host $(6,12 ; \mathrm{H}$. V. Amerson, unpublished data), no progress has been made on identifying and mapping the corresponding Avr genes in the pathogen. Currently, progenies from select loblolly pine trees known to harbor specific Fr genes are being planted across different geographic sites to assess Fr gene stability (H. V. Amerson, unpublished data). Although this procedure allows one to indirectly measure the frequency of avr

Corresponding author: T. L. Kubisiak; E-mail address: tkubisiak@fs.fed.us

DOI: 10.1094/PHYTO-95-0376

This article is in the public domain and not copyrightable. It may be freely reprinted with customary crediting of the source. The American Phytopathological Society, 2005. alleles in natural populations of the pathogen, it is operationally cost prohibitive and may not be a good indicator of temporal pathogen variability. However, if predictive markers in strong linkage disequilibrium with Avr genes were known in the fungus they could provide a direct assessment of specific avr and Avr allele frequencies in pathogen populations in any year without the necessity of inoculation trials on differential host families. Such information would ultimately provide a quick and reliable means by which more informed management decisions could be made regarding appropriate host Fr gene deployment.

As a first step toward this goal, we propose a method for mapping C. quercuum f. sp. fusiforme Avr genes using DNA markers. Briefly, a host family segregating for a specific previously mapped Fr gene (in our case Fr1) (12) is challenged with a fungal culture known to be segregating at the corresponding Avr1 gene. Known molecular markers in the host are used to distinguish genetically resistant $(F r 1 / f r 1)$ from susceptible $(f r 1 / f r 1)$ trees. Based on the gene-for-gene model, only $a v r 1$ basidiospores can infect and cause a gall to form on Fr1/fr1 trees, where as either $a v r 1$ or $A v r 1$ basidiospores can infect and cause a gall on fr $1 / f r 1$ trees. Hence, DNA markers linked with the Avr1 locus should segregate independently in fungi assayed from $f r 1 / f r 1$ trees, but those same markers should not segregate or should show significant segregation distortion in fungi assayed from Fr1/fr 1 trees. This differential infection of $f r 1 / f r 1$ versus $F r 1 / f r 1$ trees should allow us to identify markers linked to the Avr1 locus. To assess the feasibility of this approach, we performed experiments to meet the following objectives: (i) to determine if individual spermatia (pycnial drops) consist of only a single haploid genotype; (ii) to determine if the current artificial inoculation procedure results in multiple infections in a single gall, and if so, how frequently; (iii) to determine if Avr1 basidiospores could 
cause infection of $F r 1 / f r 1$ trees in the presence of avr1 basidiospores, i.e., could $a v r 1$ basidiospores ever predispose some $F r 1 / f r 1$ trees to possible infection by Avr1 basidiospores; and (iv) do $a v r 1$ and Avr1 basidiospores equally infect $f r 1 / f r 1$ trees. If multiple infection does occur and pycnial drops always consist of more than a single genotype or if some sort of predisposition of a Fr1/fr1 host to infection by Avr1 spores was possible under high inoculum loads, then Avr1 gene mapping using our approach would not be feasible. In order to address these questions, a basidiospore blending or competition experiment was conducted and analyzed with a set of microsatellite DNA markers.

\section{MATERIALS AND METHODS}

Rust and pine sources and inoculation procedures. Rehydrated urediniospores $(n+n)$ derived via single-aeciospore $(n+n)$ culture techniques (7) were sprayed on the ventral surfaces of immature leaves of seedlings of northern red oak (Quercus rubra L.) to produce telial columns. Three weeks after inoculation, infected oak leaves with telial columns were used to produce basidiospores. The infected leaves were suspended above acidified distilled water ( $\mathrm{pH} 2.2$ ), and basidiospores (n) were cast into the acidified water to prevent premature germination. Basidiospores were filtered from the acidified water onto cellulose nitrate filter disks with a $3 \mu \mathrm{M}$ pore size. The filtered spores were washed with $\mathrm{pH} 6.0$ distilled water and then suspended in $\mathrm{pH} 6.0$ water. Basidiospores of each isolate used were adjusted to 100,000 spores per ml with a particle counter (Coulter Model B; Coulter Electronics, Inc., Hialeah, FL). Basidiospores derived from the dikaryotic isolate SC20-21 known to be homozygous Avr1/Avr1 to fusiform rust resistance gene $F r 1$ were blended in equal proportions (1:1) with basidiospores derived from isolate NC2-36 deduced to be homozygous avr1/avr1 (6). This mixture was used to inoculate 6-week-old open-pollinated (OP) progenies of loblolly pine family 10-5 known to be segregating for $F r 1$ resistance $(6,12)$ using the concentrated basidiospore spray system (CBS) (8). Basidiospore collections and pine seedling inoculations were conducted at the USDA Resistance Screening Center (RSC) in Asheville, NC.

DNA extraction and marker assessments of rust and pine sources. DNA was extracted from urediniospores and basidiospores with a modified cetyltrimethylammonium bromide (CTAB) extraction procedure (2) and a grinding matrix derived from the work of Zambino (13). The same grinding matrix was used with pycniospores that were extracted following a modified Qiagen DNeasy protocol (Qiagen DNeasy 96 Plant Kit Handbook, 1999; Qiagen, Valencia, CA) or via initial grinding in CTAB lysis buffer coupled with final steps that followed a modified Qiagen DNeasy protocol. Although any one of these modified protocols will likely yield DNA of sufficient quality for enzyme manipulation from all the various spore stages of $C$. quercuum $\mathrm{f}$. sp. fusiforme used in this study, modifications were made in an attempt to further increase quantity and/or quality and hence are described as used. In the CTAB protocol, spores were placed in a grinding tube with $0.5 \mathrm{~g}(0.8 \mathrm{~mm})$ zircon spheres, $12.5 \mathrm{mg}$ of diatomaceous earth, 1 (0.25 in.) ceramic sphere, and $2 \times$ CTAB lysis buffer ( $2 \%$ hexadecyltrimethylammonium bromide, $1.4 \mathrm{M} \mathrm{NaCl}, 20 \mathrm{mM}$ EDTA, and $100 \mathrm{mM}$ Tris- $\mathrm{HCl}, \mathrm{pH} 8.0$, and $1 \%$ polyvinylpyrrolidone) containing $1 \%$ mercapto-ethanol and proteinase $\mathrm{K}$ at $0.1 \mu \mathrm{g} / \mu \mathrm{l}$. Samples were ground with a Bio-101 Thermo Savant grinder (Carlsbad, CA). Basidiospores in 525 to $700 \mu$ of $2 \times$ CTAB lysis buffer were ground once for $30 \mathrm{~s}$ at speed setting 5 . Urediniospores in $250 \mu \mathrm{l}$ of the above $2 \times$ CTAB lysis buffer were initially ground for $20 \mathrm{~s}$ at speed setting 5 followed by the addition of $275 \mu \mathrm{l}$ of the above $2 \times$ CTAB buffer and a second grinding of $20 \mathrm{~s}$ at speed setting 5. Pycniospores in 200 to $325 \mu \mathrm{l}$ of $2 \times$ CTAB lysis buffer were ground initially for $30 \mathrm{~s}$ at speed setting 5 followed by adjustment of total buffer volume to $525 \mu \mathrm{l}$ and grinding for an additional $10 \mathrm{~s}$ at speed setting 5. Following grinding, all samples were incubated in a $65^{\circ} \mathrm{C}$ water bath for at least $30 \mathrm{~min}$. Next, 700 to $800 \mu \mathrm{l}$ of $24: 1$ chloroform/isoamyl alcohol (CIA) was added per sample and briefly mixed, and the samples were subjected to centrifugation at $10,000 \times g$ for $15 \mathrm{~min}$. The supernatant for each sample was transferred to a new tube and a second CIA step (700 $\mu$ l of CIA plus $50 \mu \mathrm{l}$ of $10 \%$ CTAB [hexadecyltrimethylammonium bromide] in $0.7 \mathrm{M} \mathrm{NaCl}$ ) was performed followed by centrifugation at $10,000 \times g$. For basidiospore and urediniospore samples, the supernatant was again transferred to a new tube and the DNA was precipitated by adding 1/10th-volume of $3 \mathrm{M}$ sodium acetate with 2 volumes of ice-cold isopropanol. The samples were then stored at $20^{\circ} \mathrm{C}$ for at least $45 \mathrm{~min}$. The DNA was pelleted by centrifugation at $15,000 \times g$ for $15 \mathrm{~min}$ and subsequently washed with $70 \%$ ethanol. The final DNA pellet was lyophilized and resuspended in 50 or $100 \mu \mathrm{l}$ of TE (10 mM Tris, 0.1 mM EDTA, pH 8.0) with RNase A at $0.5 \mu \mathrm{g} / \mu \mathrm{l}$.

For pycniospore samples initially ground in CTAB, after the second CIA step, 375 to $400 \mu \mathrm{l}$ of aqueous supernatant was mixed with $600 \mu \mathrm{l}$ of Qiagen AP3E buffer, with each sample then being pipetted to a Qiagen DNeasy 96 well plate. The plate was centrifuged at $5,635 \times g$ for $5 \mathrm{~min}$ to bind the DNA to the Qiagen matrix. Each well was washed with $800 \mu \mathrm{l}$ of Qiagen buffer AW followed by centrifugation at $5,635 \times g$ for $15 \mathrm{~min}$. Next, $100 \mu \mathrm{l}$ of 1/4-strength Qiagen buffer AE or $100 \mu$ l of full-strength AE buffer was added to each well and the DNeasy plate was centrifuged at $5,635 \times g$ for 2 min to elute DNA. This elution step was repeated yielding $200 \mu \mathrm{l}$ per sample for both the full-strength and 1/4-strength elutions. Samples eluted in the 1/4-strength buffer were next lyophilized and resuspended in $50 \mu \mathrm{l}$ of molecular grade water to yield samples in full-strength AE. RNase A at a final concentration of $0.5 \mu \mathrm{g} / \mu \mathrm{l}$ was added to the eluted DNA.

For pycniospore samples ground in Qiagen AP1 lysis buffer plus RNase A at a concentration of $0.25 \mu \mathrm{g} / \mu \mathrm{l}$, the same grinding matrix was employed. Samples were initially ground in $325 \mu$ of the AP1 RNase A buffer for $30 \mathrm{~s}$ at speed setting 5 followed by the addition of $200 \mu \mathrm{l}$ of the same AP1 RNase A buffer and a second grinding for $10 \mathrm{~s}$ at speed setting 5. Samples were incubated for $30+\min$ at $65^{\circ} \mathrm{C}$. Next, $200 \mu$ of Qiagen AP2 buffer was added to each sample for protein precipitation and samples were maintained in an ice bath for $30+$ min. Upon removal from the ice bath, samples were centrifuged at $13,000 \times g$ for at least $10 \mathrm{~min}$. Five hundred microliters of each sample was transferred to a 96 well block and individually mixed with $750 \mu \mathrm{l}$ of Qiagen AP3E buffer. Each AP3E/extract sample was transferred to a Qiagen DNeasy 96 well plate. The plate was centrifuged at 5,635 $\times$ $g$ for 5 min to spin down DNA bound to the Qiagen matrix. Each well was washed with $1 \mathrm{ml}$ of Qiagen buffer AW followed by centrifugation at $5,635 \times g$ for $15 \mathrm{~min}$. One hundred microliters of half-strength Qiagen buffer AE was added to each well and the DNeasy plate was centrifuged at $5,635 \times g$ for 2 min to elute DNA. This step was repeated, ultimately yielding DNA in $200 \mu \mathrm{l}$ of half-strength AE buffer.

Rust microsatellite DNA marker protocols followed previously described procedures (5). Alleles at as many as 10 microsatellite loci were found to be informative for discriminating between the single-aeciospore-derived isolates SC20-21 and NC2-36 (Table 1). These same loci were also useful for discriminating among infecting genotypes or gametothalli derived from each of the isolates. Assuming that alleles at these loci are unlinked, it would be possible to detect as many as 512 unique gametothalli from SC20-21 (number of alleles ${ }^{\text {number of heterozygous loci }}=2^{9}=512$ ) and as many as 1,024 unique gametothalli from NC2-36 $\left(2^{10}=1,024\right)$.

For loblolly pine, megagametophyte DNA extractions and random amplified polymorphic DNA (RAPD) marker protocols followed previously described procedures (3). RAPD marker J7_470 (previously called J7_485), which is tightly linked with 
the $F r 1$ locus in tree $10-5(6,12)$, was used to discriminate between trees having inherited the $F r 1$ resistance allele versus those having inherited the $f r 1$ nonresistance allele from parent 10-5. The work of Wilcox et al. (12) presented evidence suggesting that the Fr1 allele was rare in the pollen pool, and our control inoculation in this study with isolate SC20-21 further confirms this. As a control, a set of 60 OP $10-5$ progeny marker genotyped for the presence of $F r 1$ versus $f r 1$ inherited from the 10-5 parent were inoculated with basidiospores $(100,000$ spores per $\mathrm{ml})$ derived from isolate SC20-21 (Avr1/Avr1) to assess the potential for Fr1 resistance in the pollen pool. Thirty progeny were designated as having $F r 1$, while 30 others were designated as having $f r 1$. As expected, the 30 progeny inheriting fr 1 from the $10-5$ parent were galled, indicating no evidence for the $\mathrm{Fr} 1$ allele in the pollen pool, thus confirming its rarity as previously suggested (14). Additionally, all $30 \mathrm{Fr} 1$ progeny remained gall-free, confirming the absence of $a v r 1$ in isolate SC20-21. Given these data and previously published work (12), the pollen pool contribution to our study progeny is deemed to be $f r 1$, and our study trees are genotypically designated as resistant $(F r 1 / f r 1)$ and susceptible $(f r 1 / f r 1)$. A total of 53 pycnia producing galled trees $(28 \mathrm{Fr} 1 / \mathrm{fr} 1$ and $25 \mathrm{fr} 1 / \mathrm{fr} 1)$ from the 1:1 blended basidiospore inoculation were included in this study to assess the four objectives previously stated in the introduction.

Pycnial induction and determination of infection genotypes. At 6 months postinoculation, galled trees were placed in incubation chambers and subjected to 14 days of 16-h photoperiod at $10^{\circ} \mathrm{C}$ to induce the formation of pycnial drops. Subsequent to the cold treatment, trees were moved to a covered growing area and drops were harvested starting $\approx 10$ to 14 days later and collected over a period of $\approx 7$ days. Single drops were harvested from fr $1 / f r 1$ trees, whereas only aggregate or bulk collections of drops were harvested from Fr1/fr 1 trees. DNA was extracted and assessed using the microsatellite markers as described previously to determine if the drops were single or mixed genotypes (objective 1). In order to determine the minimum number of infection events that could be detected in each of the $f r 1 / f r 1$ trees (objective 2), we first focused on only those drops that were a single haploid genotype based on the microsatellite DNA markers. From these data, unique or unambiguous infecting genotypes or gametothalli were noted. Next, we focused on the mixed or multiple-genotype drops within each tree to determine which unique gametothalli were likely contributing spores to the mixed drops. Microsatellite allele peak height data were used to assist in the determination of

TABLE 1. Microsatellite marker alleles amplified from urediniospore DNA for single-aeciospore-derived fusiform rust isolates SC20-21 and NC2-36 ${ }^{\mathrm{a}}$

\begin{tabular}{llcc}
\hline Marker & Isolate & Allele 1 & Allele 2 \\
\hline Cqf045 & SC20-21 & 226 & 252 \\
& NC2-36 & 236 & 271 \\
Cqf065 & SC20-21 & 438 & 446 \\
& NC2-36 & 446 & 448 \\
Cqf078 & SC20-21 & 157 & 157 \\
& NC2-36 & 151 & 155 \\
Cqf083 & SC20-21 & 167 & 173 \\
& NC2-36 & 150 & 171 \\
Cqf084 & SC20-21 & 162 & 166 \\
& NC2-36 & 166 & 172 \\
Cqf088 & SC20-21 & 250 & 264 \\
& NC2-36 & 248 & 250 \\
Cqf096 & SC20-21 & 187 & 197 \\
& NC2-36 & 177 & 189 \\
Cqf0151 & SC20-21 & 328 & 342 \\
& NC2-36 & 288 & 328 \\
Cqf0165 & SC20-21 & 269 & 291 \\
& NC2-36 & 259 & 265 \\
Cqf0166 & SC20-21 & 384 & 492 \\
& NC2-36 & 378 & 420 \\
\hline
\end{tabular}

a Allele size is reported to the nearest base pair. the most likely mix of haploid genotypes. If or when new or previously undetected alleles were observed, the presence of an additional infection or gametothallus was noted. Finally, we tested bulked drops collected from Fr1/fr 1 trees to determine if any SC20-21 alleles could be detected (objective 3 ) and test the null hypothesis that SC20-21 and NC2-36 equally infect fr1/fr 1 trees (objective 4).

\section{RESULTS}

Detection sensitivity of microsatellite markers. To investigate the detection sensitivity of the microsatellite markers, basidiospore DNA was assessed. Basidiospores from the single-aeciospore-derived urediniospore line SC20-21 were blended either 50:50, 95:5, or 99:1 with basidiospores from the single-aeciospore-derived urediniospore line NC2-36 or with basidiospores derived from a mixed aeciospore line (L-12, provided by C. Young at RSC). Individual nonblended samples of all three lines were also available. DNA was extracted from these various spore populations and used for microsatellite marker analysis. Basidiospores derived from the urediniospore lines SC20-21 and NC2-36 were found to have no more than two marker alleles at any one locus and the alleles present were consistent with those found in parental urediniospore lines (Table 1). Analysis of mixed line L-12 showed a variety of alleles at some loci as expected (data not shown). In the blended lines, the lesser source was detectable at $1 \%$ or greater and the $99: 1$ blends were easily recognized as mixed DNAs (data not shown). This suggested that the detection sensitivity was at least $1 \%$.

fr1/fr 1 susceptible trees. A total of 230 individual pycnial drops were harvested from 25 different $f r 1 / f r 1$ trees (Table 2 ). The number of drops varied from as few as two to as many as 15 per tree, averaging 9.2. Each of these drops was genotyped using the microsatellite markers. Based on these data, 23 of the 25 trees

TABLE 2. Number of pycnial drops assayed, number of inferred infections, number of infections derived from NC2-36, and number of infections derived from SC20-21 on 25 susceptible ( $f r 1 / f r 1)$ seedlings from loblolly pine family 10-5 inoculated with a blend of basidiospores (1:1) from Cronartium quercuum $\mathrm{f}$. sp. fusiforme single-aeciospore-derived urediniospore lines SC2021 (Avr1/Avr1) and NC2-36 (avr1/avr1)

\begin{tabular}{|c|c|c|c|c|}
\hline Tree & $\begin{array}{c}\text { No. of } \\
\text { pycnial } \\
\text { drops }\end{array}$ & $\begin{array}{c}\text { No. of } \\
\text { inferred } \\
\text { infections }\end{array}$ & $\begin{array}{l}\text { No. of infections } \\
\text { derived from } \\
\text { NC2-36 }\end{array}$ & $\begin{array}{l}\text { No. of infections } \\
\text { derived from } \\
\text { SC20-21 }\end{array}$ \\
\hline 246 & 2 & 1 & 0 & 1 \\
\hline 251 & 12 & 7 & 2 & 5 \\
\hline 257 & 3 & 3 & 2 & 1 \\
\hline 263 & 10 & 6 & 3 & 3 \\
\hline 278 & 10 & 4 & 2 & 2 \\
\hline 279 & 9 & 3 & 1 & 2 \\
\hline 284 & 3 & 3 & 1 & 2 \\
\hline 299 & 9 & 5 & 2 & 3 \\
\hline 302 & 12 & 5 & 4 & 1 \\
\hline 304 & 10 & 5 & 2 & 3 \\
\hline 309 & 4 & 3 & 0 & 3 \\
\hline 314 & 14 & 7 & 3 & 4 \\
\hline 315 & 13 & 6 & 3 & 3 \\
\hline 317 & 2 & 2 & 1 & 1 \\
\hline 319 & 11 & 4 & 2 & 2 \\
\hline 320 & 15 & 4 & 2 & 2 \\
\hline 321 & 6 & 1 & 0 & 1 \\
\hline 323 & 15 & 6 & 1 & 5 \\
\hline 324 & 10 & 6 & 2 & 4 \\
\hline 325 & 14 & 5 & 3 & 2 \\
\hline 338 & 9 & 4 & 1 & 3 \\
\hline 340 & 14 & 3 & 1 & 2 \\
\hline 341 & 14 & 4 & 1 & 3 \\
\hline 342 & 7 & 3 & 0 & 3 \\
\hline 343 & 2 & 2 & 1 & 1 \\
\hline Total & 230 & 102 & 40 & 62 \\
\hline Mean & 9.2 & 4.08 & $\ldots$ & $\ldots$ \\
\hline
\end{tabular}


were infected by more than one basidiospore suggesting that multiple infections are common using the CBS inoculation method (8). Of the 230 drops assayed, 99 (43\%) were found to contain only a single allele at each marker suggesting that each was derived from a single pycnium. The other 131 drops were found to contain more than one allele for at least one marker locus suggesting that they consisted of a mixture of pycniospores that arose from pycnia of more than one gametothallus. Even though we were careful to collect what appeared to be specific drops, we suspect that physical mixing between or among drops arising from pycnia of genetically different gametothalli is the most likely mechanism to account for mixed genotype drops.

Of the 230 drops analyzed from the $25 \mathrm{fr} 1 / \mathrm{fr} 1$ trees, a total of 102 unique infection events or gametothalli were observed (Table 2 ). The number of putative infections per tree ranged from as few as one to as many as seven, averaging 4.08. Based on our genetic model, an $f r 1 / f r 1$ tree can become infected by either an $a v r 1$ or Avr1 basidiospore. Assuming that there are no differences in aggressiveness of the isolates as well as no fitness costs associated with unnecessary virulence we would expect to find roughly equal numbers of $a v r 1$ and $A v r 1$ basidiospore infections. Of the 102 individual infection events observed, 40 were caused by avr 1 basidiospores (spores from isolate NC2-36), whereas 62 were caused by Avr1 basidiospores (spores from isolate SC20-21) $\left(\chi^{2}=4.75\right.$; significant at $\left.P=0.05\right)$. This suggests that there may be either (i) a difference between these isolates in terms of their aggressiveness on $f r 1 / f r 1$ progeny of loblolly pine family $10-5$; or (ii) a possible fitness cost associated with unnecessary virulence. When allele peak height data were used to identify the predominant haploid genotype within each drop this difference became even more evident. For the 221 drops where a predominant genotype could be unambiguously identified, in 69 an avr1 genotype predominated and in 152 an $A v r 1$ genotype predominated $\left(\chi^{2}=\right.$ 31.12; significant at $P<0.001$ ) suggesting that infecting Avr1 genotypes may be either more aggressively colonizing host tissues or producing more spermatia.

Fr1/fr 1 resistant trees. A total of 64 bulked collections of spermatia were harvested from the $28 \mathrm{Fr} 1 / \mathrm{fr} 1$ trees. The number of bulk collections varied from as few as one to as many as four per tree, averaging 2.3. Based upon microsatellite marker analysis, again multiple infections were common using the CBS inoculation method. All $28 \mathrm{Fr} 1 / \mathrm{fr} 1$ trees were infected by more than one basidiospore based on the presence of two alleles for at least one marker locus. As would be predicted by our genetic model, alleles characteristic of only the avr1/avr1 isolate (NC2-36) were detected in the bulk pycnial drop collections from $\mathrm{Fr} 1 / \mathrm{fr} 1$ trees. These data strongly suggest that Avr1 basidiospores of SC20-21 origin are unable to infect $F r 1 / f r 1$ trees even in the presence of avr1 basidiospores at high inoculum densities. In other words, the presence of $a v r 1$ basidiospores does not appear to predispose an Fr1/fr1 tree to possible infection by Avr1 basidiospores. If Avr1 basidiospores were able to infect, the resulting gametothalli are either unable to sporulate or their level of sporulation is below the limit detectable by the microsatellite markers. Given that both $a v r 1$ and Avr1 infections were easily distinguishable in the $f r 1 / f r 1$ trees, albeit not at equal frequencies, we feel that the latter possibilities are not likely.

\section{DISCUSSION}

In nature, the preponderance of fusiform rust galls appear to consist of a single haploid genotype or gametothallus suggesting that they are the result of infection by just a single basidiospore (5). On the contrary, there is evidence to suggest that multiple basidiospores can cause infection under artificial inoculation conditions. Using RAPD markers, Doudrick et al. (1) observed polymorphisms among single pycnial drops harvested from three of four loblolly pine trees that were inoculated using a forced-air system (12 to 18 spores per $\mathrm{mm}^{2}$ ) (11). Using the CBS method, Schmidt and Miller (10) observed a direct correlation between the percentage of seedlings showing production of aeciospores and inoculum concentration $(r \approx 0.7$ in slash pine and $r \approx 0.8$ in loblolly pine) and attributed this to an increased number of hyphal anastomoses between compatible mating types under high inoculum concentrations. Our data clearly reinforce this understanding and show without doubt that multiple infections within a single gall are the rule rather than the exception using the CBS inoculation system.

This multiple infection phenomenon has certain implications for further work on the genetics of the interaction between Pinus spp. and C. quercuum f. sp. fusiforme. For example, because multiple infection using the CBS method can result in the physical mixing of drops among pycnia from multiple gametothalli, all drops should be genotyped when single-genotype purity is a requisite, such as for recombinational linkage mapping studies. Also, because multiple infection does occur and physical mixing of drops is common, it is possible that anastomosis and karyogamy may occur without artificial transfer of spermatia onto receptive hyphae. Therefore, it should be possible to take advantage of multiple infection for producing experimental crosses of the fungus. Inbred lines or specific cross lines could be developed by simply inoculating susceptible trees using the CBS method and either a single-urediniospore isolate or a mixture of two different isolates, respectively. The use of microsatellite markers to genotype a parental isolate(s) and single-aeciospore- or single-urediniospore-derived lines obtained from these trees should unambiguously identify the origin of these spore populations (inbred or cross).

Doudrick et al. (1) also suggested that the possibility of the presence of more than one genotype within galls reinforced a belief that experiments on the genetics of the interaction between Pinus spp. and C. quercuum f. sp. fusiforme could not be carried out using the current methods of inoculation. Their major concerns appeared to be that multiple infections might potentially complicate the expression of specific resistance in the host and/or complicate segregation patterns in the fungus. Our data show that multiple infections are the rule using CBS inoculations; however, there is no evidence to suggest that the genetics of the gene-forgene system are ever compromised. When both avr1 and Avr1 basidiospores were mixed, only avr 1 basidiospores were observed to cause infection on $F r 1 / f r 1$ trees, whereas both $a v r 1$ and $A v r 1$ basidiospores were observed to cause infection on $f r 1 / f r 1$ trees, albeit not at equal frequencies. Although we cannot use these data to determine the most likely cause for the observed difference in infection frequency between $a v r 1$ and Avr1 basidiospores (differences in aggressiveness between the two isolates or fitness costs associated with harboring an unnecessary virulence allele), these results do suggest that further experiments designed to specifically address this issue are warranted.

The results reported here are a first step toward identifying markers genetically linked to C. quercuum f. sp. fusiforme Avr genes using DNA markers. With this knowledge, we have already undertaken efforts to map the Avr1 locus. If successful, this effort will represent the first recognition of a marker-defined Avr gene in $C$. quercuum f. sp. fusiforme and will provide a model for further investigation. Additional studies seeking other Avr genes could provide information regarding the organization of these genes in $C$. quercuum f. sp. fusiforme (i.e., are they linked or independent). Markers linked with the Avr1 locus can serve as the subjects of linkage disequilibrium assessments in inoculation trials. If predictive markers in linkage disequilibrium are consistently detected in inoculation trials, they expectedly could provide a tentative assessment of Avr1 allele frequencies in selected pathogen populations without the necessity of inoculation trials. Once the gene sequences are known or markers within these sequences are developed, then these features can be used with 
certainty to assess the occurrence and frequency of Avr1 alleles across the pathogen population.

\section{ACKNOWLEDGMENTS}

We thank G. Kuhlman (retired USDA Forest Service) for allowing access to the single-aeciospore-derived cultures of $C$. quercuum $\mathrm{f}$. sp. fusiforme; C. Young at the Resistance Screening Center (USDA Forest Service, Forest Health Protection) for generating basidiospores and performing the CBS pine inoculations; S. Garcia (NC State University) for skilled technical assistance with RAPD marker detection in loblolly pine and DNA extractions from the fungus; C. Burdine (Southern Institute of Forest Genetics) for aid in collection of pycnial drops and skilled technical assistance with microsatellite polymerase chain reaction; and S. Josserand (Southern Institute of Forest Genetics) for skilled technical assistance with microsatellite marker detection on the ABI 3100 DNA analysis machine.

\section{LITERATURE CITED}

1. Doudrick, R. L., Nance, W. L., Nelson, C. D., Snow, G. A., and Hamelin, R. 1993. Detection of DNA polymorphisms in a single urediniosporederived culture of Cronartium quercuum $\mathrm{f}$. sp. fusiforme. Phytopathology 83:388-392.

2. Doyle, J. J., and Doyle, J. L. 1990. Isolation of plant DNA from fresh tissue. BRL Focus 12:13-15.

3. Jordan, A. P. 1997. Fusiform rust disease resistance and genomic mapping in loblolly pine. MS thesis. Dept. Forestry, North Carolina State University, Raleigh.

4. Kinloch, B. B., Jr., and Walkinshaw, C. H. 1991. Resistance to fusiform rust in southern pines: How is it inherited? Pages 219-228 in: Rusts of
Pine. Proc. IUFRO Rusts of Pine Working Party Conf. Y. Hiratsuka, J. K. Samoil, P. V. Blenis, P. E. Crane, and B. L. Laishley, eds. Inf. Rep. NORX-317, Edmonton, Canada.

5. Kubisiak, T. L., Roberds, J. H., Spaine, P. C., and Doudrick, R. L. 2004. Microsatellite DNA suggests regional structure in the fusiform rust pathogen Cronartium quercuum f. sp. fusiforme. Heredity 92:41-50.

6. Kuhlman, E. G., Amerson, H. V., Jordan, A. P., and Pepper, W. D. 1997. Inoculum density and expression of major gene resistance to fusiform rust disease in loblolly pine. Plant Dis. 81:597-600.

7. Kuhlman, E. G., and Matthews, F. R. 1993. Variation in virulence among single-aeciospore isolates from single-gall isolates of Cronartium quercuum f. sp. fusiforme. Can. J. For. Res. 23:67-71.

8. Matthews, F. R., and Rowan, J. 1972. An improved method for large-scale inoculations of pine and oak with Cronartium fusiforme. Plant Dis. Rep. 56:931-934.

9. Nelson, C. D., Doudrick, R. L., Nance, W. L., Hamaker, J. M., and Capo, B. 1994. Specificity of host-pathogen genetic interaction for fusiform rust disease on slash pine. Pages 403-411 in: Proc. So. For. Tree Improv. Conf., 22nd. U.S. Dep. Agric. For. Serv., Atlanta, GA.

10. Schmidt, R. A., and Miller, T. 1999. Influence of inoculum concentration on production of spermagonia and aecia on pine seedlings infected by basidiospores of Cronartium quercuum f. sp. fusiforme. Plant Dis. 83:367370.

11. Snow, G. A., and Kais, A. G. 1972. Technique for inoculating pine seedlings with Cronartium fusiforme. Pages 325-326 in: Biology of Rust Resistance in Forest Trees. Proc. NATO-IUFRO Adv. Study Inst. 1969, Moscow, ID. U.S. Dept. Agric. Misc. Publ. 1221

12. Wilcox, P. L., Amerson, H. V., Kuhlman, E. G., Lui, B. H., O'Malley, D. M., and Sederoff, R. 1996. Detection of a major gene for resistance to fusiform rust disease in loblolly pine by genomic mapping. Proc. Natl. Acad. Sci. 93:3859-3864.

13. Zambino, P. J. 2002. Dry grinding at near ambient temperatures for extracting DNA from rust and other fungal spores. BioTechniques 33:48-51. 